\title{
Remembering Arthur Robinson
}

\author{
Judy M. Olson \\ Department of Geography \\ Michigan State University
}

onto maps, to their content and structure, and their role and impact in human activity, past and present. Neither background in geography nor artistic skills are required.

[Description of GEOG 111: Maps and Mapping, University of Kansas Undergraduate Catalog 1975-2005]

\author{
Ph.D. 1970, University of Wisconsin, Madison \\ The Effects of Class Interval Systems on the Visual \\ Correlation of Choropleth Maps
}

A rthur H. Robinson, "Robbie," was my PhD advisor at the University of Wisconsin. That is far from a unique honor; he advised no fewer than 14 Phd students during his career, and I was one of the last he took on. Perhaps it was all the advising experience before I came along that made him such an expert guide, and that he was. My tribute to Robbie here will start with my experiences as a graduate student and then move on to The American Cartographer and to more recent personal memories of this wonderful man.

My first memory of Robbie when I was a graduate student is somewhat vague, but I do remember how I felt-in awe that I was glimpsing the author of that textbook I had been reading as an undergraduate. He looked-so human. Since my master's work was not in cartography, and since Joel Morrison was teaching several of the cartography courses by the time I matriculated at UW, the only lecture course I took from Robbie was the History of Cartography. Even though I was not a specialist in the history of the field and was not particularly enamored of history courses in general at that time, I found Robbie's class extremely enlightening, and to this day I remember many of the things he talked about. His lectures were well organized and, if not particularly dynamic, very easy to listen to, and my fellow graduate students and I absorbed the content and often discussed it out of class. Like all UW geography courses that included both graduate and undergraduates, History of Cartography had a "grad section," an extra meeting at regular intervals (every other week perhaps) of just the graduate students and professor. A term assignment went along with it. I chose to look at the press coverage of the controversy stir-red up by The Vinland Map and the Tartar Relation, the first (1965) edition of which had been released on or just before Columbus Day (or perhaps it was just the news of it, but I distinctly remember the involvement of Columbus Day). After giving my report, Robbie asked if I thought they chose that day on purpose, and green young graduate student that I was I said oh, no, I didn't think they would have done that. He very matter-of-factly said "Oh, I think they did" and went on to the next report. He offered no further argumentation and had not stated it as a put-down; it was just an understated hint that opened my eyes to the whole phenomenon of rivalry in the world of publishing and in academics.

The comment is one of many that stuck with me through the years. A small phrase would open up a whole new understanding. Sometimes 
it was an aphorism. "You can't edit your own work" (referring to himself as well as those of us listening), "Don't be a slave to consistency [in writing]," and the quotation "Never use a preposition to end a sentence with," come back to me in Robbie's deep voice.

While I was working on my master's thesis I became very interested in the research going on in cartography at the time. In addition to sheer interest, I had a practical bent, I had debated about cartography as the direction to go with the master's, and I was picking up signals that cartography would be a good field to be in over subsequent years. Not surprisingly, I decided to shift emphasis for the PhD. I would have to give the credit to Joel Morrison and to fellow cartography graduate studentsKaren Severud (Cook), David Woodward, and others-for inspiring me to go in that direction. But when it came to selecting an advisor, I sought Robbie's input (probably feeling too lowly to ask him outright) and he simply said that for the type of dissertation I had in mind he should and would be my advisor.

I am sure he must have had moments of regret (not too many I hope). One of my biggest challenges as a graduate student resulted from having chosen to minor in statistics, which required, in addition to applications courses, a year-long sequence in mathematical statistics, an experience not for the faint of heart. I sat in on calculus through multiple integration and differentiation in preparation, but even the math majors in the math stats class had difficulty, and the first exam had me in Robbie's office suggesting a change of program. In his usual calm manner, he suggested that I just keep going with what I had set out. Fortunately, my low grade on the exam, demoralizing as it was, was relatively high on the curve (no one would have passed without use of a grading curve in the class) and my attitude toward the class changed during the review of the exam when I recognized the usefulness of the solution to one of the problems. Without Robbie's sage advice, I probably would not have been there to hear what that problem had been about. There were definite advantages to the esteem in which we held our advisors at that time.

Another conversation that I found memorable took place a few weeks before Robbie's graduate seminar in which I participated (the only non-lecture course I had from him). He came into the Cartography Lab where I was working, probably on some errand, but seeing me he sat down and asked what I thought should be the theme of the seminar. It had never occurred to me that someone might ask my opinion about course content, but I swallowed my shock and told him what I had been finding interesting in the reading I had been doing. He said yes, psychophysics would be a good topic and, I assume with the input of other enrollees as well, that was the theme. It was from the seeds of that seminar and from another that was led by Joel Morrison that my dissertation, with its two distinctive but interrelated parts, developed. Had he not asked us, I am not sure what the theme would have been that year. It was an interesting lesson to me about being in tune with student interests.

Robbie was never one to over-emphasize his role in such matters as funding of graduate students, but I do remember that one year I was given a small scholarship by the University that was (unbeknownst to me) misunderstood by the department to be a full ride for the year. Since the scholarship, despite its paltry size, precluded taking an assistantship, I received no word of renewal when everyone else did. Robbie was chair at the time, and worried about what I was going to do without a graduate assistantship, I went to his office and broached the subject. He looked at me with alarm and told me to sit down while he checked up on what had 
happened. He returned in minutes to inform me of the misunderstanding and to tell me my funding was restored.

Later I needed funding to print materials for my dissertation, an amount that was trivial, I suppose, but would have been a burden for me. He made sure I got the funding for it from somewhere within the University, and given my vague recollections of the whole process, I suspect he played a significant role in the application.

Probably the most memorable and appreciated incident in my relationship with him as a graduate student was his handling of the reading of my dissertation. I had accepted a position at the University of Georgia early in the year and wanted to be finished before I left in August. When the dissertation was approaching the finishing stages that summer, he informed me that I should call him when it was ready and I could drop it off at his house. I did. Four days later he called to say he was finished with it and I could pick it up again. I did the last revisions and took it to the typist, who would make a clean copy of my portable-typewriter draft with my corrections as well as Robbie's on it. My defense was in August, with my full committee present, and I was finished and off to Georgia. I wish I could report that I returned my own PhD students' dissertations in four days.

As I started my academic career, one of the organizations in which I participated was the American Congress on Surveying and Mapping (ACSM). It was within that organization that Robbie was encouraging the development of an American cartographic journal. Robbie's diplomatic skills and his goodwill among ACSM colleagues as well as his vision for the new journal led to a favorable outcome on the matter. Either just before or just following the decision, Robbie called me at the University of Georgia and wondered if I would be the Associate Editor. He was very specific about the title being Associate Editor and not Assistant, and I doubt I understood the significance of that at the time. Although I do not recall his ever saying anything about discrimination in academia, I suspect he was well aware that women could not have the image of "assistant" if they were to make it in their careers (he never suggested putting his name on anything from my dissertation either). To say the invitation was unexpected is an understatement, but I talked with colleagues about it and decided to accept the post of Associate Editor of the as yet unnamed journal that launched as The American Cartographer in April of 1974. As I have indicated in a tribute to Robbie in Cartography and Geographic Information Science, which is the current title of that journal, he gave me independence in handling my share of manuscripts. He consulted on various issues and kept me informed and was in effect, if not intent, grooming me to be the next editor, something I would have been altogether unable to do without some experience. He had considerable influence on the journal, but he launched it to exist on its own and accepted not only that it would change and evolve over time, but that others would have control of those changes.

On the human side, there is an image from the planning meeting for the journal that especially stands out in my mind. Robbie was sitting in the lobby of the Disney World hotel where ACSM was meeting (Fall '73). I suppose I expected him to be bored with the trappings of a theme park, but as I approached he pointed over at an awestruck youngster being greeted by the Disney character Goofy. At the time I was wishing I had a camera to catch the youngster. Later I wished I had been able to take a picture of Robbie enjoying the sight of the youngster with the big old lovable Goofy. Robbie was quite capable of seeing and enjoying the magic of the Magic Kingdom as he waited for the meeting that was to be crucial to a journal that has survived for over 30 years. 
I turned to Robbie for advice from time to time in the early years of my career and occasionally even later on. He was willing to offer it, but even in the early years, he never offered a lot of it. He did not micromanage his students either before or after they graduated. He made sure in his own way that we were launched in our careers, but like the new journal, we were intended to continue on our own.

My most recent memories of Robbie are due to some fortuitous events. One was that I decided, enroute, to travel through Madison on my way to central Wisconsin last summer. Staying over night at my sister's house, I called Robbie in the morning and asked if he would like a visitor. I received a hearty response and proceeded to the condo to visit Robbie and his wife Martha. He was in good humor and engaged readily in conversation. I showed him some materials from a current (unusual) research project and he was very interested to hear what I had been working on. He wondered when I was going to retire and when I said I hadn't quite decided, he said "Well, I highly recommend it!" As with many statements from Robbie, I was caught by surprise. Here was a gentleman who had changed the cartographic world admitting, albeit indirectly, that he had been happy to finish his career and enjoy retirement. We visited for an hour or so before I headed north.

In October, I was in Madison for David Woodward's memorial service and was fortunate enough to have the company of Karen Cook, also one of Robbie's students and my roommate in graduate school. We contacted Robbie and Martha and invited them to dinner on Saturday evening and to ride with us to the memorial service on Sunday. They, in turn, invited us to dinner on Sunday evening, and it was wonderful contact with them, albeit under the very sad circumstances of the loss of David, which was especially poignant for Robbie, who had outlived another of his favorite students. Robbie was ambulatory but frail and his eyesight had been deteriorating over several years. His mind was sharp, however, and remaining vision sufficient that he competently navigated for us. As usual, he was interested in what we were doing and was especially interested to hear about China and the 2001 ICA Conference, an event both Karen and I had attended.

That was the weekend of October 3. Robbie passed away one week later. Our intention of honoring David with our presence at his memorial service had turned into a goodbye to Robbie as well.

\section{A Lifelong Curiosity about Maps}

\author{
Ph.D. 1978, University of Wisconsin, Madison \\ Lithographic Maps in the Nineteenth Century \\ Geographical Journals
}

After finishing my Ph.D. under Arthur H. Robinson's supervision in 1978, my association with him evolved from a formal student-professor relationship into a friendship. Chances to meet in person were infrequent but treasured occasions. When I visited Madison in 1997, Robbie and Martha graciously welcomed me into their home. The following are his reminiscences about the beginning of his career taken from a conversation that I recorded during that visit.

\author{
Karen Severud Cook \\ Spencer Research Library \\ University of Kansas
}

